\title{
A MARCAÇÃO DA \\ MODALIDADE DEÔNTICA NO \\ PARESI
}

\author{
LA MARCACIÓN DE LA MODALIDAD DEÓNTICA EN PARESI
}

MARKING OF DEONTIC MODALITY IN PARESI

Núbia Ferreira Rech*

Universidade Federal de Santa Catarina

Ana Paula Brandão*

Universidade Federal do Pará

\begin{abstract}
RESUMO: Neste artigo, apresentamos uma descrição e análise da partícula maika em Paresi, uma língua indígena falada por aproximadamente 3000 pessoas no estado do Mato Grosso. Nossa pesquisa teve por base dados retirados de textos ou elaborados por consultores falantes nativos do Paresi. Nosso aporte teórico foi os estudos de Brennan (1993), Hacquard (2006, 2010), Palmer (1986), von Fintel (2006), Pires de Oliveira e Rech (2016) e Rech e Varaschin (2017, no prelo). Constatamos que o Paresi apresenta marcações distintas para as modalidades deôntica e epistêmica. Estas são expressas através de partículas: maika e kala, respectivamente. Nossa análise, ainda em etapa inicial, sinaliza que maika corresponde a uma partícula indicadora de modalidade deôntica do tipo ought-to-be, quando ocorre com segunda pessoa; e ought-to-do, quando ocorre com terceira pessoa.
\end{abstract}

PALAVRAS-CHAVE: Paresi. Modalidade deôntica. Sintaxe. Semântica.

RESUMEN: En este artículo, presentamos una descripción y análisis de la partícula maika en Paresi, una lengua indígena hablada por aproximadamente 3000 personas en el Estado de Mato Grosso. Nuestra investigación tuvo como base datos recopilados de textos o elaborados por consultores hablantes nativos del Paresi. El aporte teórico fue los estudios de Brennan (1993), Hacquard (2006, 2010), Palmer (1986), von Fintel (2006), Pires de Oliveira y Rech (2016) y Rech y Varaschin (2017, en prensa). Constatamos que el Paresi presenta marcas distintas para las modalidades deónica y epistémica. Estas se expresan a través de partículas: maika y kala, respectivamente. Nuestro análisis, aún en etapa inicial, señala que maika corresponde a una partícula indicadora de modalidad deóntica del tipo ought-to-be, cuando ocurre con segunda persona; y ought-to-do, cuando ocurre con tercera persona. PALABRAS CLAVE: Paresi. Modalidad deóntica. Sintaxis. Semántica.

ABSTRACT: In this article, we present a description and analysis of the maika particle in Paresi, an indigenous language spoken by approximately 3000 people in the state of Mato Grosso. Our research was based on data taken from texts or given by consultants who were Paresi native speakers. Our theoretical framework consisted on the studies of Brennan (1993), Hacquard (2006, 2010), Palmer (1986), von Fintel (2006), Pires de Oliveira and Rech (2016) and Rech and Varaschin (2017, forthcoming).

\footnotetext{
* Professora do Programa de Pós-Graduação em Linguística e do Departamento de Língua e Literatura Vernáculas da UniversidadeFederalde Santa Catarina (UFSC). E-mail: nubiarech@pq.cnpq.br

**ProfessoradaFaculdadede Letras da UniversidadeFederaldo Pará (UFPA). E-mail: apbrandao7@gmail.com.
} 
We found out Paresi presents distinct markers for deontic and epistemic modalities. These are expressed through the particles: maika and kala, respectively. Our analysis, still in an initial stage, indicates maika corresponds to a particle that indicates ought-tobe deontic modality, when it occurs with the second person; and ought-to-do, when it occurs with the third person.

KEYWORDS: Paresi. Deontic modality. Syntax. Semantics.

\section{INTRODUÇÃO}

Neste artigo, nos propomos a descrever e analisar o emprego da partícula maika em Paresi. Esta língua pertence à família Aruák e é falada no Mato Grosso por uma população de aproximadamente 3000 pessoas. Os dados do Paresi foram retirados de um banco de dados de texto ou elaborados durante a pesquisa, com a colaboração de consultores falantes nativos de Paresi. ${ }^{1}$ Supomos que maika constitui um marcador de modalidade deôntica no Paresi, proposta que discutiremos ao longo do artigo com a apresentação de alguns indícios nessa direção. Um dos nossos objetivos aqui é criar a base para que se possa avaliar, no Paresi, a hipótese de Pires de Oliveira e Rech (2016), de que deônticos precisam checar o traço agentividade [+Ag] com um dos participantes do evento ao qual são relativizados. Essa hipótese poderá ser testada apenas quando avançarmos na descrição dos recursos para a expressão da modalidade nessa língua. Até o momento, constatamos que o Paresi apresenta mais de uma marca para indicar diferentes interpretações modais: kala - modalidade epistêmica; e maika - modalidade deôntica.

O Paresi é uma língua indígena brasileira com uma descrição gramatical razoável em comparação com outras línguas indígenas². Mesmo assim, ainda há muito a ser investigado. Os estudos do Paresi a que tivemos acesso não descrevem, por exemplo, a marcação de modalidade deôntica nessa língua, nosso foco de investigação neste artigo. Pires de Oliveira e Rech (2016) assumem que há dois tipos de deônticos, conforme Brennan (1993) e Hacquard (2006, 2010): (i) deônticos ought-to-do, em que a obrigação ou permissão recai sobre um participante do evento descrito pelo VP, normalmente o sujeito da sentença; e (ii) deônticos ought-to$b e$ em que a ordem/obrigação ou permissão recai sobre um participante do evento de fala: o addressee. O participante sobre o qual recai a orientação do modal irá checar o traço [+Ag], licenciando, assim, a interpretação deôntica em posição baixa (ought-to-do); ou em posição alta (ought-to-be). Essa proposta sinaliza que o componente sintático determina, pelo menos em parte, a interpretação do modal. Logo, a modalidade corresponderia a um fenômeno de interface sintaxe-semântica, como argumenta Hacquard $(2006,2010)$.

O Paresi, por exibir um sistema de alinhamento semântico ${ }^{3}$, no qual é marcada a distinção entre predicados agentivos e não agentivos, pode lançar luzes sobre o estudo dos núcleos modais no português brasileiro (PB) e demais línguas nominativas. Isso porque, de acordo com a proposta de Pires de Oliveira e Rech (2016), as propriedades do predicado sob o escopo do modal podem interferir na sua interpretação. Para investigarmos essa hipótese no Paresi, é necessário, antes, identificar a marcação de modalidade deôntica nessa língua e mapear os contextos em que figura, nosso principal objetivo neste artigo. Nosso aporte teórico para a descrição e análise de maika como um marcador de modalidade deôntica no Paresi é Palmer (1986), Brennan (1993), von Fintel (2006), Hacquard (2006, 2010) e Pires de Oliveira e Rech (2016).

O artigo está organizado de forma a, na seção 1, apresentar dados de línguas de tipologias diferentes - o PB e o Paresi - que fundamentam a proposta de Pires de Oliveira e Rech (2016) para a interpretação dos deônticos. Na seção 2, apresentamos uma descrição de maika, justificando nossa hipótese de que se trata de uma partícula (subseção 2.1) e que corresponde a um marcador de modalidade deôntica (subseção 2.2). Por fim, tecemos algumas considerações sobre o emprego da partícula maika com verbos na segunda e terceira pessoas.

\footnotetext{
1 O banco de dados contém textos que foram coletados, transcritos e traduzidos por Brandão e consultores do Paresi durante o período de 2006 a 2014 . Alguns dados com maika foram extraídos de sentenças elaboradas por consultores falantes nativos de Paresi que atuam como colaboradores do projeto "Modalidade deôntica e traço de controle em Português e Paresi”, da Universidade Federal do Pará (Portaria 012/2016).

${ }^{2}$ Ver Silva (2009, 2013); e Brandão (2010, 2014).

${ }^{3}$ A denominação 'alinhamento semântico' é mais genérica que os termos 'ergatividade cindida' e 'intransitividade cindida', que se aplicam exclusivamente a línguas acusativas ou ergativas. O termo 'alinhamento semântico' assume apenas que os fatores que afetam o tratamento diferencial dos sujeitos de verbos intransitivos é semântico, podendo envolver papéis semânticos, aspecto e aspecto lexical (DONOHUE; WICHMANN, 2008).
} 


\section{PREDICADOS AGENTIVOS E NÃO AGENTIVOS E A INTERPRETAÇÃO DEÔNTICA OUGHT-TO-DO}

Em Paresi, os verbos podem ser identificados de acordo com a valência verbal e o papel semântico de seus sujeitos. Em termos da valência, os verbos podem ser intransitivos, transitivos ou bitransitivos; em termos de papel semântico dos seus sujeitos, os verbos intransitivos podem ser classificados ainda em agentivos ou não-agentivos, dependendo do tipo de proclítico de pessoa que eles tomam. A divisão no grupo de verbos intransitivos no Paresi é marcada morfologicamente da seguinte forma: i) alguns verbos intransitivos recebem a mesma marcação de sujeito que os verbos transitivos (os proclíticos do grupo A com a vogal $a$ ); ii) enquanto outros recebem uma marcação de sujeito diferente (os proclíticos do grupo B).

\begin{tabular}{c|c|c} 
& Grupo A & Grupo B \\
\hline $1 \mathrm{sg}$ & $\mathrm{na}=$ & $\mathrm{no}=$ \\
\hline $2 \mathrm{sg}$ & $\mathrm{ha}=$ & $\mathrm{hi}=$ \\
\hline $3 \mathrm{sg}$ & $\varnothing=$ & $\emptyset=$ \\
\hline $1 \mathrm{pl}$ & $\mathrm{wa}=$ & $\mathrm{wi}=$ \\
\hline $2 \mathrm{pl}$ & $\mathrm{za}=$ & $\mathrm{xi}=$ \\
\hline $3 \mathrm{pl}$ & $\varnothing=\ldots-\mathrm{ha}$ & $\varnothing=\ldots-\mathrm{ha}$
\end{tabular}

Tabela 1: grupos dos proclíticos em Paresi Fonte: Brandão (2014, p. 81)

De acordo com Brandão (2014), os verbos que recebem os marcadores do grupo A são aqueles cujos participantes são atores que performam a situação denotada pelo predicado. Verbos que recebem marcadores do grupo B são aqueles cujos participantes são undergoers, ou seja, não performam o evento descrito pelo predicado. Vejamos os exemplos a seguir:

(1)

$$
\begin{aligned}
& \text { a. na=zawatya haira }{ }^{4} \\
& 1 S G=\text { jogar bola } \\
& \text { 'Eu joguei a bola.' }(E)^{5}
\end{aligned}
$$

b. na=tona (argumento de verbo inergativo)

$1 \mathrm{SG}=$ caminhar

'Eu caminhei' (E)

no=waini-hena (argumento de verbo inacusativo)

$1 \mathrm{SG}=$ morrer-TRS

'Eu vou morrer.'

(BRANDÃO, 2014, p. 24).

No Paresi, o caso correspondente ao argumento externo de verbos transitivos coincide com o caso dos pronomes que figuram com verbos monoargumentais de ação, denominados inergativos, como se verifica em (1a, 1b). Já o caso correspondente ao argumento de predicados inacusativos é distinto, conforme (2).

\footnotetext{
4 AFF-Afectivo, BEN-Benefactivo, COP-Copula, DEO-Deôntico, ENF- Ênfase, EPIST-Epistêmico, IFV-Imperfectivo, LOC-locativo, M-Masculino, NEGNegação, NMLZ-Nominalizador, O-Objeto, PERF-Perfectivo, PL-Plural, SG-Singular, TOP-Tópico, TRS-Transicional, VM- Voz média.

${ }^{5}$ A fonte dos exemplos do banco de dados Paresi é especificada através dos seguintes códigos: T indica que os exemplos são de textos; e E indica que os exemplos foram elaborados pelos consultores falantes nativos do Paresi.
} 
É importante notar ainda que o Paresi atribui marcação de caso distinta a pronomes que se adjungem a predicados estativos, evidenciando uma diferença no interior dessa classe: alguns estativos figuram com proclíticos do grupo A, enquanto outros figuram com proclíticos do grupo B. Nos exemplos a seguir, é possível verificar esse contraste:

(3)

a. na=waiye-ze-hekola

1SG=ser.bom-NMLZ-?

'Eu sou prudente' (E)

b. na=waiye-ze-hare

$1 \mathrm{SG}=$ ser.bom-NMLZ-M

'Eu sou uma pessoa legal' (E)

(BRANDÃO, 2014, p. 234).

(4)

\author{
a. no=waxirahare \\ $1 \mathrm{SG}=$ ser.feio \\ 'Eu sou feio' (E) \\ b. no=maira \\ $1 \mathrm{SG}=$ ter.medo \\ 'Eu tenho medo' (E) \\ (BRANDÃO, 2014, p. 241).
}

Os exemplos de (1) a (4) revelam que a distribuição de caso gramatical no Paresi não pode ser explicada por uma oposição entre a classe dos estativos e as demais classes aspectuais (atividades, accomplishments e achievements), em que a primeira, por ser marcada com o traço [-dinâmico], não figuraria com pronomes com caso correspondente a argumentos agentivos; e as demais, por serem marcadas com o traço [+dinâmico], figurariam com pronomes com caso agentivo na função de sujeito. A ocorrência de predicados estativos com pronomes flexionados tanto no caso associado a argumentos agentivos, conforme (3a, 3b), quanto no caso associado a argumentos não agentivos, conforme (4a, 4b), indica que há estados passíveis de controle, conforme já sinalizado em Parsons (1990), Basso e Ilari (2004) e Rech e Varaschin (no prelo). Destacamos que o sistema de distribuição de casos no Paresi apresenta evidências de que a marcação de caso não é arbitrária e, ainda, aponta a importância da noção semântica de agentividade/controle para esse sistema.

Em línguas nominativas, os predicados estativos não carregam marcas morfológicas que nos permitam distinguir entre os passíveis e os não passíveis de controle. Cabe observar, entretanto, que apenas parte dos estativos - aqueles que figuram com proclíticos do grupo A no Paresi - ocorrem na forma progressiva. Observemos o exemplo a seguir, transcrito de Parsons (1990, p. 35):

$$
\begin{aligned}
& \text { John is being silly (... being a fool). } \\
& \text { John está sendo bobo (... um tolo) }
\end{aligned}
$$

Para o autor, a ocorrência do progressivo com be silly ou be a fool revela que estes predicados exibem propriedades eventivas em (5), remetendo ao modo como John age em determinada situação, e não a uma marca do seu caráter. Neste caso, John comporta-se como um tolo ao realizar algum(ns) evento(s), como contar piadas ou convidar insistentemente uma garota para sair, em uma situação específica, que pode ser durante uma festa, por exemplo. Logo, o uso destes predicados pressupõe, neste contexto, um argumento com traços agentivos. Nossa proposta para explicar os casos de estativos do Paresi que se combinam com marcadores do Grupo A é a de que estativos passíveis de controle podem corresponder a uma eventualidade incrementada, que contém subeventos que resultam na manifestação da propriedade descrita pelo predicado estativo, à semelhança do que Rothstein (2004) propõe para inacusativos achievements relacionados a movimento em direção a um lugar físico, como arrive (chegar), que se combinam com o aspecto progressivo e, igualmente, resultam de subeventos realizados por um participante agentivo $^{6}$.

${ }^{6}$ Ver Rech e Varaschin (2017). 
A marcação de caso no Paresi revela que alguns predicados - inergativos, transitivos, inacusativos achievements associados a deslocamento no espaço e estativos passíveis de controle - descrevem eventos em que atua (direta ou indiretamente) um participante agentivo; enquanto outros - demais inacusativos e estativos não passíveis de controle - não. É interessante observar que os primeiros correspondem a predicados que licenciam interpretação deôntica do tipo ought-to-do (em que a obrigação ou permissão recai sobre o sujeito da sentença) no $\mathrm{PB}$, ao passo que os outros correspondem a predicados que oferecem restrição a este tipo de interpretação, conforme Pires de Oliveira e Rech (2016); e Rech e Varaschin, (2017, no prelo). Vejamos alguns exemplos a seguir:

a. Mariana deve trabalhar neste final de semana.

$\left(\operatorname{Mod}_{\text {Deôntico }}\right)$

b. Mariana deve morrer neste final de semana.

$\left(\operatorname{Mod}_{\text {Deôntico }}\right)$

A sentença (6a) pode ser empregada em contextos nos quais a obrigação é orientada para o sujeito da sentença: a responsabilidade sobre a realização do evento recai sobre Mariana; ou para o addressee, que deve garantir que Mariana realize o evento descrito na sentença. No primeiro caso, o modal deve é classificado como um deôntico do tipo ought-to-do. Segundo Hacquard (2006), este tipo de deôntico é relativizado ao evento descrito pelo VP, tendo acesso a seus participantes - dentre os quais está o sujeito da sentença, o que permite sua interpretação em posição baixa. No segundo caso, o modal corresponde a um deôntico ought-to-be, sendo relativizado ao evento de fala e a seus participantes; é interpretado, portanto, em posição alta. Já a sentença (6b) não permite essas duas interpretações para o deôntico. Pires de Oliveira e Rech (2016), em estudo experimental sobre os deônticos, constataram que os falantes do PB atribuem ao deôntico apenas a interpretação do tipo ought-to-be quando este forma sequência com um predicado como morrer. A leitura deôntica disponível para a sentença (6b) é aquela em que a ordem/obrigação recai sobre o addressee, que deve garantir a realização do evento Mariana morrer neste final de semana.

As sentenças do exemplo (6) mostram que a interpretação ought-to-do não está sempre disponível ao deôntico. Pires de Oliveira e Rech (2016) e Rech e Varaschin (2017), assumindo que modais são relativizados a eventos, conforme Hacquard (2006, 2010), propõem que o deôntico precisa checar o traço $[+\mathrm{Ag}]$ com um dos participantes do evento ao qual está relativizado. De acordo com esses autores, a interpretação deôntica ought-to-do requer a presença de um participante agentivo em posição baixa (integrando o evento descrito no VP), o qual é selecionado por predicados inergativos e transitivos, mas não por inacusativos. Esta proposta dá conta de explicar as diferenças entre (6a) e (6b) em relação à interpretação deôntica ought-to-do, uma vez que em (6b) o modal é relativizado a um evento descrito por um predicado inacusativo; logo, sem um participante agentivo.

A restrição à interpretação deôntica do tipo ought-to-do também foi verificada em construções com alguns predicados estativos, justamente com aqueles que correspondem aos marcados com proclíticos do grupo B no Paresi. Nas sentenças do exemplo a seguir, apresentamos casos em que o modal deve forma sequência com estativos passíveis de controle, em (7a), e não passíveis de controle, em (7b-c):

(7) a. Carlos deve ser cauteloso na reunião.

( Ought-to-be/ J Ought-to-do)

b. Joana deve ser alta.

$\left({ }^{*}\right.$ Ought-to-be $/{ }^{*}$ Ought-to-do)

c. A protagonista da nova série deve ser alta.

( Ought-to-be ${ }^{*}$ Ought-to-do)

Conforme Rech e Varaschin (no prelo), o estativo ser cauteloso é passível de controle, mediante o controle que o argumento deste predicado (Carlos) pode exercer sobre eventos que resultem no estado ser cauteloso (na reunião), tais como: analisar os pronunciamentos dos outros membros antes de fazer uma proposta, ponderar antes de tomar uma decisão, calcular os riscos de uma negociação, analisar pós e contras etc. Por Carlos ter controle sobre um conjunto de eventos que acarretam o estado ser cauteloso, o 
deôntico em (7a) pode ser interpretado em posição baixa, como um ought-to-do. A interpretação ought-to-be também está disponível para (7a), responsabilizando o ouvinte (addressee) - um participante do evento de fala - por garantir a eventualidade descrita na sentença: Carlos ser cauteloso na reunião. Nas sentenças (7b) e (7c), o predicado estativo sob o escopo do modal não é passível de controle; logo, a restrição à interpretação deôntica do tipo ought-to-do já era esperada. Não faz sentido dar uma ordem ou responsabilizar alguém pela manifestação de propriedade sobre o qual não se tem controle, como ser alto. (7b) não admite nenhum tipo de interpretação deôntica porque nem Joana (sujeito da sentença) nem qualquer outra pessoa (um participante do evento de fala - o addressee) tem controle sobre a altura de Joana. Já a sentença (7c) admite a interpretação deôntica ought-to-be, por o DP sobre o qual recai a propriedade ser alta não ter ainda sua referência definida. Neste caso, o addressee recebe a ordem para monitorar o processo de seleção da protagonista de tal forma que o resultado seja a escolha de um referente que já manifeste a propriedade ser alta, e não para monitorar a propriedade em si, que não é passível de monitoramento.

Segundo o que vimos argumentando, a interpretação ought-to-do só estará disponível ao modal quando houver um participante agentivo no evento descrito pelo VP para checar o traço [+Ag] do deôntico. Por isso, é esperada a interpretação deôntica ought-todo em construções com predicados inergativos e transitivos, mas não com inacusativos ou estativos. Rech e Varaschin (2017) mostram, entretanto, que o modal pode ser interpretado como um deôntico ought-to-do em construções com predicados inacusativos. Os autores argumentam que inacusativos achievements relacionados a movimento em direção a um lugar físico, como chegar, sair, entrar, surgir, aparecer, desaparecer..., correspondem a culminação de evento(s) passível(is) de ser(em) controlado(s) por um participante com a mesma referência do argumento do inacusativo. Com base em Rothstein (2004), os autores assumem que o evento descrito pelo VP corresponde, neste caso, a uma estrutura incrementada cujo predicado inacusativo descreve o ponto de culminação de um accomplishment derivado. Logo, nas fases preparatórias do evento descrito no VP, há um participante agentivo que pode checar o traço [+Ag] do deôntico, licenciando, assim, uma interpretação do tipo ought-to-do. Essa interpretação não está disponível em construções com inacusativos como nascer, crescer, cair, florescer..., por estes descreverem eventos que não podem ser controlados por um participante com a mesma referência do argumento do inacusativo. Os autores estendem essa proposta aos predicados estativos (RECH; VARASCHIN, no prelo), que também podem ser subclassificados em passíveis e não passíveis de controle, como sinaliza a marcação de caso agentivo e não agentivo em Paresi.

Nosso propósito neste artigo é investigar uma possível marcação de modalidade deôntica no Paresi: a partícula maika. Se a hipótese de autores como Pires de Oliveira e Rech (2016) e Rech e Varaschin (2017, no prelo) estiver correta, não apenas para o PB, mas também para outras línguas naturais como o Paresi, é esperado que uma leitura deôntica orientada para o sujeito da sentença só ocorra com predicados que no Paresi figuram com proclíticos do grupo A. Nas seções subsequentes, passamos à análise de maika no Paresi, argumentando a favor de que se trata de uma partícula indicadora de modalidade deôntica. Conforme sinalizamos na introdução, o mapeamento das marcas de modalidade no Paresi é importante para investigar, nessa língua, a hipótese de que o predicado sob o escopo do modal exerce influência na sua interpretação. Essa investigação será possível apenas depois de avançarmos no conhecimento das marcas de modalidade no Paresi. Com este artigo, pretendemos contribuir com essa descrição.

\section{MODALIDADE DEÔNTICA EM PARESI: O CASO DE MAIKA}

\subsection{MORFOSSINTAXE DA PARTÍCULA MAIKA}

Segundo Lyons (1977), a modalidade tem suas raízes na lógica modal dentro da filosofia da linguagem, a qual a relaciona com as noções de necessidade e possibilidade. As duas principais categorias são as modalidades deôntica e epistêmica. A modalidade deôntica está relacionada mais especificamente à necessidade e à possibilidade de atos performados por agentes responsáveis moralmente, sendo caracterizada pela obrigação e permissão (LYONS, 1977; PALMER, 1986). Já a epistêmica está relacionada ao conhecimento do falante em relação a uma proposição (PALMER, 1986; KRATZER, 2012).

Van der Auwera e Ammann (2013) e Bybee et al. (1994) observam que há marcações distintas para as modalidades deôntica e epistêmica nas línguas por eles investigadas, diferentemente do que ocorre em línguas como o português brasileiro (PB), o inglês, $\mathrm{O}$ italiano e o espanhol, em que um mesmo item lexical pode expressar mais de um tipo de modalidade. Como exemplos de línguas 
com marcação diferente para modalidade deôntica e epistêmica, podemos citar Paresi (BRANDÃO, 2014), Evenki (van der AUWERA; AMMANN, 2013), Stat'imcets (MATTHEWSON et al., 2005), Gitksan (MATTHEWSON ET AL., 2013), Javanês (VANDER KLOK, 2008) e Kakataibo (VALLE, 2015). Uma das questões a ser abordada neste artigo refere-se ao tipo de marca usada para expressar modalidade deôntica no Paresi.

De acordo com van der Auwera e Ammann (2013) e Cinque (1999, 2006), a noção de modalidade pode ser expressa por afixos, por auxiliares modais ou, ainda, por outros tipos de marcadores, tais como partículas e advérbios. Temos por hipótese que a modalidade deôntica no Paresi é marcada por partícula, conforme argumentamos ao longo desta subseção.

Partículas correspondem a morfemas independentes fonologicamente e sem marcas de morfologia nominal nem verbal, conforme Zwicky (1985). O fato de não receberem morfemas flexionais diferencia as partículas dos verbos, que podem receber marcas de pessoa, mudança de valência (causativos, recíproco, voz média) e morfemas de aspecto. O comportamento das partículas em relação à flexão não as diferencia, entretanto, da classe dos advérbios, que também não ocorrem com morfemas flexionais. Segundo Cruschina (2010), as principais propriedades que permitem distinguir partículas de advérbios nas línguas naturais são as seguintes: (i) partículas são palavras funcionais, pertencendo, portanto, a uma classe fechada; já os advérbios correspondem a uma classe aberta; (ii) partículas não podem ser coordenadas, enquanto advérbios podem figurar com um outro advérbio na sentença.

Conforme Brandão (2014), no Paresi essas diferenças não se sustentam. Os advérbios pertencem a uma classe fechada nessa língua, semelhante às partículas, e correspondem a apenas um tipo semântico: advérbios temporais. Estes podem ocorrer na posição inicial da sentença, como em (8), ou na posição final, como em (9):

(8)

$\begin{array}{llll}\text { kalini } & \text { wi=wawa } & \text { wi=tsaon-ita } & \text { witso-ta } \\ \text { hoje } & 1 P L=\text { sozinho } & 1 P L=C O P-I F V & 1 P L-E N F\end{array}$

'Hoje nós estamos sozinhos' (BRANDÃO, 2014, p.132).

(9)

$\begin{array}{lllll}\text { maitsa } & \text { ala } & \text { maiha } & \varnothing=\text { tyo-ita } & \text { kalini } \\ \text { NEG } & \text { EPIST } & \text { NEG } & 3 S G=v i r-I F V & \text { hoje }\end{array}$

'Eu acho que ele não vem hoje' (E)

Já as partículas podem estar associadas a categorias como negação, modalidade e aspecto. Cabe observar que, no Paresi, nenhuma partícula ocorre no final da sentença, diferenciando-se, assim, dos advérbios. Na próxima seção, ilustramos esse emprego a partir de exemplos com maika, que, de acordo com nossos dados, não ocorre na última posição da sentença.

\subsection{MAIKA - MARCADOR DE MODALIDADE DEÔNTICA}

A partícula maika foi primeiramente descrita como uma marca de sugestão cortês por Brandão (2014). Nossa hipótese é de que essa partícula expressa modalidade deôntica, com um uso, preferencialmente, como diretivo, caracterizando um ato de fala performativo - com marcação explícita de segunda pessoa. Essas propriedades são comuns tanto a construções em que ocorre um deôntico alto (do tipo ought-to-be) quanto a construções imperativas. O que nos leva a supor que maika corresponde a uma partícula indicadora de modalidade deôntica - e não de imperativo - é sua ocorrência também com terceira pessoa, com sujeito explícito por sintagma nominal. 
O uso de maika pode expressar tanto obrigação (10) como permissão (11), como vemos nos exemplos abaixo com segunda pessoa:

(10) Contexto: Diana gosta de comer chocolate o tempo todo quando está de férias.

Então, Marina, a mãe de Diana, antes de ir trabalhar, dá a seguinte instrução à babá:

maika makani weta taita chocolateDiana ana $\mathrm{h}=\mathrm{itsa}$

DEO amanhã cedo apenas chocolateDiana BEN 2SG=dar

'Você deve dar para Diana chocolate apenas de manhã cedo'/ Dê para Diana chocolate apenas de manhã cedo/.'. (E)

\author{
Paula, maika $\quad \mathrm{h}=$ ehokot $y-o a^{7}$ \\ Paula DEO 2SG=deitar-VM \\ 'Paula, pode deitar' (BRANDÃO, 2014, p. 229).
}

O exemplo (10) ilustra o emprego de maika como ordem/obrigação, com sujeito expresso por proclítico de segunda pessoa $(h=)$. Este mesmo proclítico aparece em (11), em que maika assume uma conotação de permissão. Tanto em (10) quanto em (11), a partícula maika é empregada como diretivo ${ }^{8}$; mais especificamente, tem um uso performativo, impondo uma obrigação ou dando uma permissão ao interlocutor (addressee), que, nestes exemplos, é correferencial ao sujeito da sentença. Considerando que, nestes casos, a modalidade deôntica - de ordem/obrigação e permissão - é orientada para um participante do evento de fala (o addressee) e está ancorada no tempo de fala, associamos esses empregos de maika ao deôntico alto (do tipo ought-to-be). Cabe observar a ocorrência, em nossos dados, de maika com segunda pessoa em narrativas sobre fatos no passado, mas apenas em trechos com discurso direto, conforme (12):

$\begin{array}{lllll}\text { "maika } & \mathrm{x}=\text { itse-het-ene } & \text { enomanaFUNAI nali" } & \varnothing=\text { neye } \\ \text { DEO } & \text { 2SG=dar-PERF-3O } & \text { BEN } & \text { FUNAI LOC } & \text { 3SG=dizer }\end{array}$

"Eles diziam: ' - Você deve entregar isto para ele na Funai'" (T)

Em (12), à semelhança dos exemplos (10) e (11), maika figura com marca de segunda pessoa, recaindo a obrigação sobre o addressee. Por tratar-se de um ato performativo, o tempo da ordem é ou o momento da fala, como em (10) e (11), ou o momento da fala reportada em situações de discurso direto, como em (12). Observa-se que as informações acessadas para a interpretação de maika - tanto no que se refere ao participante sobre o qual recai a orientação do modal quanto sobre o tempo da ordem - são disponibilizadas a partir do evento ao qual o modal é relativizado. Por isso, nos exemplos de (10) a (12), vimos associando maika à interpretação deôntica alta (ought-to-be). É importante notar, entretanto, que o ato performativo está associado também à forma imperativa. Assim, o uso performativo de maika por si só não é suficiente para sua classificação como deôntico ought-to-be. Por essa razão, passamos a apresentar propriedades da forma imperativa no Paresi em contraste com a partícula maika.

O imperativo é um tipo de sentença básica (SADOCK; ZWICKY, 1985), que em geral expressa comando, isto é, impõe uma obrigação ao ouvinte (von FINTEL; IATRIDOU, 2017). Segundo von Fintel e Iatridou (2017) e Alcázar e Saltarelli (2014), o imperativo, além de expressar comando, pode ter outros usos considerados fracos, como por exemplo: permissão, pedido, exigência, desejo, súplica, convite e conselho. Outras propriedades de imperativos em geral são: i) estar associado ao tempo presente (momento da fala) ou futuro/irrealis; e ii) ser relativizado a eventos controláveis, requerendo um participante agentivo (ALCÁZAR; SALTARELLI, 2014).

\footnotetext{
${ }^{7}$ Este exemplo foi empregado em um contexto no qual o falante dava permissão à pesquisadora para deitar em sua rede.

${ }^{8}$ Segundo Lyons (1977), diretivos são enunciados que impõem, ou propõem, alguma tomada de ação ou padrão de comportamento e indicam que o mesmo deve ser executado. Incluem comandos, exigências, pedidos, súplicas e alertas, exortação e recomendação.
} 
No Paresi, semanticamente, as sentenças no imperativo são usadas para expressar obrigação, permissão, conselho ou convite. Nessa língua, o imperativo não é marcado morfologicamente, aproximando-se nessa propriedade do inglês ${ }^{9}$, conforme Brandão (2014). Em sentenças imperativas, como as do exemplo (13) a seguir, o verbo pode aparecer com marca de segunda pessoa e sem marcas de tempo ou aspecto, conforme (13a); ou pode aparecer com marca de segunda pessoa e marca de aspecto transicional (-hena também usada no futuro), conforme (13b) e (13c). Cabe observar, ainda, que essas construções possuem um padrão entonacional distinto do correspondente a sentenças declarativas e interrogativas.

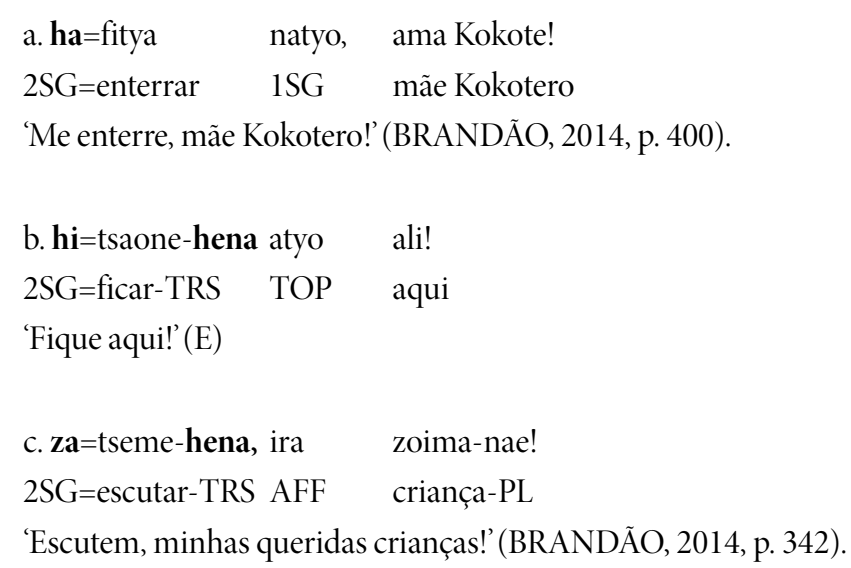

Em (13a), o verbo fitya (enterrar) aparece com marca de segunda pessoa do singular (ha=). Em (13b) e (13c), os verbos tyaona (ficar) e tsema (escutar) exibem, além da marca de segunda pessoa (singular $h i=$ e plural $z a=)$, marcação de aspecto (-hena).

Note que, em Paresi, um contexto de obrigação ou permissão envolvendo um ato performativo pode ser expresso através de uma sentença imperativa, como em (13); ou de uma sentença com maika, como nos exemplos de (10) a (12). A relação estreita entre o imperativo e a modalidade deôntica é apontada em trabalhos como os de Palmer (1986), Bybee et al. (1994), Portner (2007), Kaufmann (2012) e von Fintel e Iatridou (2017). De acordo com Palmer (1986), o imperativo se assemelha em muitos aspectos ao sistema deôntico, ou melhor, a um subsistema chamado de diretivo. O que nos levou a descartar a hipótese de que maika corresponderia a uma marca de imperativo foi sua ocorrência com morfema de terceira pessoa em nossos dados, conforme mostram as sentenças em (14) na sequência.

Há duas construções possíveis para expressar obrigatoriedade com o verbo na terceira pessoa em Paresi: (i) ocorrência de maika com sujeito expresso por um sintagma nominal (SN) e o verbo com morfema zero, indicador de terceira pessoa, conforme (14a); e (ii) ocorrência de maika com sujeito marcado apenas através do morfema zero de terceira pessoa; este caso ocorre quando o referente que corresponde ao sujeito já foi mencionado como um SN no discurso, conforme (14b):
a. maika=ra baba Zatyamare $\emptyset=$ aitse-hena hozore [...], ama Kokote, $\varnothing=$ nea
$\mathrm{DEO}=\mathrm{AFF}$ pai Zatyamare $3 \mathrm{SG}=$ matar-TRS robalo mãe Kokote $3 \mathrm{SG}=$ dizer
"'Meu pai Zatyamare deverá matar robalo, minha mãe Kokotero', ela disse"
b. eaotseta maika wakamo $\quad \boldsymbol{\emptyset}=$ aitse-hena its=ene no=mani

então DEO tuvira 3SG=matar-TRS dar-3O 1SG=BEN
'Então, deverá matar tuvira e me dar' (T)

O exemplo (14a) apresenta uma construção sintática em que o sujeito é expresso por sintagma nominal (baba Zatyamare). Nesta sentença, o sujeito está posposto à partícula maika e anteposto ao verbo. Já em (14b), o sujeito é marcado pelo morfema zero de terceira pessoa, cujo referente é recuperável no contexto.

${ }^{9}$ Conforme Palmer (1986, p. 29), em sentenças do inglês o imperativo não é marcado formalmente, como se verifica em Come in! (Entre!). 
Os usos de maika com terceira pessoa, além de nos levarem a descartar a hipótese de que essa partícula é marca de imperativo, corroboram nossa análise de maika como um marcador de modalidade deôntica. Conforme argumentamos na seção 1 , a modalidade deôntica pode estar associada a um ato de fala performativo, que corresponde a uma ordem ou permissão dada ao addressee (participante de um evento de fala), como nos exemplos de (10) a (12); ou a uma asserção, quando corresponde ao relato de uma ordem/obrigação ou permissão orientada para o sujeito da sentença (participante de um evento descrito pelo VP), como em (14a, 14b). Sentenças imperativas não correspondem a asserções.

Nossos dados sinalizam que maika figura com segunda pessoa em sentenças performativas e com terceira pessoa em sentenças assertivas. Essa distribuição revela semelhanças entre essa partícula e os modais deônticos do PB, que podem igualmente ser orientados para o addressee (interlocutor) ou para o sujeito da sentença (terceira pessoa). É necessário avançar na descrição do Paresi para nos certificarmos de que maika corresponde, de fato, a um marcador de modalidade deôntica que pode ser interpretado tanto em posição alta (como um deôntico do tipo ought-to-be) quanto em posição baixa (como um deôntico ought-to-do). Os dados a que tivemos acesso até o momento sinalizam nessa direção. Para tecer considerações mais precisas, é necessária uma análise aprofundada desta partícula, investigando, inclusive, seu emprego em construções com predicados que figuram com proclíticos do grupo A, do que nos ocuparemos em pesquisas futuras.

\section{CONSIDERAÇÕES FINAIS}

Neste artigo, apresentamos uma descrição de maika como uma partícula indicadora de modalidade deôntica do tipo ought-to-be e ought-to-do. Inicialmente, apresentamos a hipótese de Pires de Oliveira e Rech (2016) de que deônticos precisam checar um traço $[+\mathrm{Ag}]$ com um participante do evento ao qual estão relativizados. Esta hipótese foi motivada por dados do Paresi e do PB.

Na sequência, na subseção 2.1, apresentamos propriedades morfossintáticas de maika, dando indícios de que se trata de uma partícula. Na subseção 2.2, argumentamos na direção de que maika corresponde a um indicador de modalidade deôntica tanto em atos performativos como em asserções. A partir da proposta de Hacquard (2006, 2010), supomos que, no primeiro caso, maika seja relativizado ao evento de fala - com orientação para o addressee, figurando com morfema de segunda pessoa; no segundo caso, seja relativizado ao evento descrito pelo $\mathrm{VP}$ - com orientação para o sujeito, figurando com terceira pessoa.

A partir dessa análise preliminar da modalidade deôntica em Paresi, pretendemos, em pesquisa futura, investigar o emprego de maika em construções com predicados que figuram com proclíticos do grupo A e do grupo B. Dessa forma, supomos ser possível testar a restrição de deônticos do tipo ought-to-do a predicados não agentivos. Esperamos que maika não forme sequência com quaisquer predicados no Paresi, à semelhança do que foi constatado para os deônticos ought-to-do no PB (cf. PIRES DE OLIVEIRA; RECH, 2016).

\section{REFERÊNCIAS}

ALCÁZAR, A.; SALTARELLI, M. The syntax of imperatives. Cambridge: Cambridge University Press, 2014.

BASSO, R; ILARI, R. Estativos e suas características. Revista Brasileira de Linguística Aplicada, Belo Horizonte, v. 4, n. 1, p. 15-26, 2004.

BRANDÃO, A. P. A reference grammar of Paresi-Haliti (Arawak). 2014. 457f. Tese (Doutorado) - University of Texas at Austin, Austin, 2014.

Verb morphology in Paresi-Haliti (Aruák). 66f. [Qualificação de Doutorado]. The University of Texas at Austin, 2010. [acesso restrito]. 
BRENNAN, V. Root and Epistemic modal auxiliary verbs. 1993. 455f. Dissertation (Ph.D.) - University of Massachusetts, Amherst, 1993.

BYBEE, J.; PERKINS, R.; PAGLIUCA, W. The evolution of grammar: Tense, Aspect and Modality in the Languages of the World. Chicago: University of Chicago Press, 1994.

CINQUE, G. Adverbs and functional heads: a cross-linguistic perspective. New York: OUP, 1999.

Restructuring and functional heads: the cartography of syntactic structures. New York: Oxford University Press, 2006.

CRUSCHINA, S. On the syntactic status of sentential adverbs and modal particles. Language Typology and Universals (STUF), Germany, v. 63, n. 4, p. 345-357, 2010.

DONOHUE, M.; WICHMANN, S. (Ed.). The Typology of Semantic Alignment. Oxford: Oxford University Press, 2008.

HACQUARD, V. Aspects of modality. 2006. 214f. Tese (Doutorado) - Massaschusetts Institute of Technology, Cambridge, 2006. On the event relativity of modal auxiliaries. Natural Language Semantics, Netherlands, v. 18, n. 1, p. 79-114, 2010.

KAUFMANN, M. Interpreting imperatives. Dordrecht: Springer, 2012.

KRATZER, A. Modals and conditionals. NewYork: Oxford University. Press, 2012.

LYONS, J. Semantics.v. 1-2. Cambridge University Press, 1977.

MATTHEWSON, L. Gitksan Modals. International Journal of American Linguistics, Chicago, v. 79, n. 3, p. 349-394, 2013.

MATTHEWSON, L; RULLMAN, H.; DAVIS, H. Modality in St'átimcets. In: INTERNATIONAL CONFERENCE ON SALISH AND NEIGHBORING LANGUAGES, 40., 2005, Vancouver. Proceedings... University of British Columbia Working Papers in Linguistics, $2005 . \quad$ p. 93-112. Disponível em: <http://semarch.linguistics.fas.nyu.edu/Archive/zRmNWFkM/Modality\%20in\%20Sttimcets.pdf>. Acesso em: 15 abr. 2017.

PALMER, R. Mood and modality. Cambridge: Cambridge University Press, 1986.

PARSONS, T. Events in the semantics of English. Cambridge (MA): MIT Press, 1990.

PIRES DE OLIVEIRA, R.; RECH, N. F. Flavors of obligation: the syntax/semantics of deontic deve in Brazilian Portuguese. Letras de Hoje, Porto Alegre, v.51, n.3, p.349-357, 2016.

PORTNER, P. Imperatives and modals. Natural Language Semantics, v. 15, n. 4, p. 351-383, 2007.

RECH, N. F.; VARASCHIN, G. Predicados inacusativos e a modalidade deôntica. Revista Letras, Curitiba, n. 96, p. 219-238, 2017. Predicados estativos e os tipos de deôntico: ought-to-do e ought-to-be. Cadernos de Estudos Linguísticos, Campinas, Universidade Federal de Campinas. [no prelo].

ROTHSTEIN, S. Structuring events: a study in the semantics of lexical aspect. Malden. MA \& Oxford: Blackwell, 2004.

SADOCK, J.; ZWICKY, A. Speech act distinctions. In syntax. In: SHOPEN, T. (Ed.). Language typology and syntactic description. v. I: Clause structure. Cambridge: Cambridge University Press, 1985. 
SILVA, G. Morfossintaxe da língua Paresi-Haliti. 2013. 602f. Tese (Doutorado) - Universidade Federal do Rio de Janeiro, Rio de Janeiro, 2013.

. Fonologia da língua Paresi-Haliti (Aruák). 319f. Dissertação (Mestrado) - Universidade Federal do Rio de Janeiro, Rio de Janeiro, 2009.

VALLE, Daniel. Modality in Kakataibo. Interdisciplinary studies on information structure, Postdam, v. 19, p.111-137, 2015.

VAN DER AUWERA, J.; AMMANN, A. Situational possibility. In: DRYER, M.; HASPELMATH, M. (Ed.). The world atlas of Language structures online. Leipzig: Max Planck Institute for Evolutionary Anthropology, 2013. Disponível em: <http://wals.info/chapter/74>. Acesso em: 20 nov. 2016.

VANDER KLOK, J. Javanese modals. In: ANNUAL CONFERENCE OF THE CANADIAN LINGUISTIC ASSOCIATION, 2008, Vancouver. Proceedings... Toronto: University of Toronto, 2008. Disponível em: <http://homes.chass.utoronto.ca/ claacl/actes2008/CLA2008_VanderKlok.pdf>. Acesso em: 15 de abr. 2016.

VON FINTEL, K.; IATRIDOU, S. A modest proposal for the meaning of imperatives. In: ARREGUI, A.; RIVERO, M.; SALANOVA, P. (Ed.). Modality across syntactic categories. New York: Oxford University Press, 2017.

ZWICKY, A. Clitics and particles. Language, Washington, v. 61, n.2, p. 283-305, 1985. 